CrossMark

Cite as

Nano-Micro Lett.

(2019) 11:2

Received: 22 October 2018

Accepted: 28 November 2018

Published online: 9 January 2019

(C) The Author(s) 2019

\section{Bimetallic Nickel Cobalt Sulfide as Efficient Electrocatalyst for Zn-Air Battery and Water Splitting}

\author{
Jingyan Zhang ${ }^{1}$, Xiaowan $\mathrm{Bai}^{2}$, Tongtong Wang ${ }^{1}$, Wen Xiao ${ }^{3}$, Pinxian $\mathrm{Xi}^{4}$, Jinlan Wang ${ }^{2}$, \\ Daqiang Gao ${ }^{1 凶}$, John Wang ${ }^{3 凶}$ \\ Jingyan Zhang and Xiaowan Bai have contributed equally to this work. \\ $\triangle$ Daqiang Gao, gaodq@1zu.edu.cn; John Wang, msewangj@nus.edu.sg \\ 1 Key Laboratory for Magnetism and Magnetic Materials of MOE, Key Laboratory of Special Function \\ Materials and Structure Design of MOE, Lanzhou University, Lanzhou 730000, People's Republic of China \\ 2 School of Physics, Southeast University, Nanjing 211189, People's Republic of China \\ 3 Department of Material Science and Engineering, National University of Singapore, Engineering Drive 3, \\ Singapore 117575, Singapore \\ 4 Key Laboratory of Nonferrous Metal Chemistry and Resources Utilization of Gansu Province \\ and The Research Center of Biomedical Nanotechnology, Lanzhou University, Lanzhou 730000, \\ People's Republic of China
}

\title{
HIGHLIGHTS
}

- Bimetallic nickel cobalt sulfide $(\mathrm{Ni}, \mathrm{Co}) \mathrm{S}_{2}$ nanosheet arrays were demonstrated as a multifunctional catalyst for OER, HER, and ORR.

- First principle calculations were performed to probe the rate-limiting step, which involves the formation of $* \mathrm{OOH}$ from $\mathrm{HO}^{-}$on the $(\mathrm{Ni}, \mathrm{Co}) \mathrm{S}_{2}$ surface.

- A water-splitting system was designed with the $(\mathrm{Ni}, \mathrm{Co}) \mathrm{S}_{2}$ serving as both cathode and anode, and a $\mathrm{Zn}$-air battery cathode electrocatalyst.

ABSTRACT The development of efficient earth-abundant electrocatalysts for oxygen reduction, oxygen evolution, and hydrogen evolution reactions (ORR, OER, and HER) is important for future energy conversion and energy storage devices, for which both rechargeable $\mathrm{Zn}$-air batteries and water splitting have raised great expectations. Herein, we report a single-phase bimetallic nickel cobalt sulfide $\left((\mathrm{Ni}, \mathrm{Co}) \mathrm{S}_{2}\right)$ as an efficient electrocatalyst for both OER and ORR. Owing to the synergistic combination of $\mathrm{Ni}$ and $\mathrm{Co}$, the (Ni,Co) $\mathrm{S}_{2}$ exhibits superior electrocatalytic performance for ORR, OER, and HER in an alkaline electrolyte, and the first principle calculation results indicate that the reaction of an adsorbed $\mathrm{O}$ atom with a $\mathrm{H}_{2} \mathrm{O}$ molecule to form a $* \mathrm{OOH}$ is the potential limiting step in the OER. Importantly, it could be utilized as an advanced air electrode material in $\mathrm{Zn}$-air batteries, which shows an enhanced charge-discharge performance (charging voltage of $1.71 \mathrm{~V}$ and discharge voltage of $1.26 \mathrm{~V}$ at $2 \mathrm{~mA} \mathrm{~cm}^{-2}$ ), large specific capacity

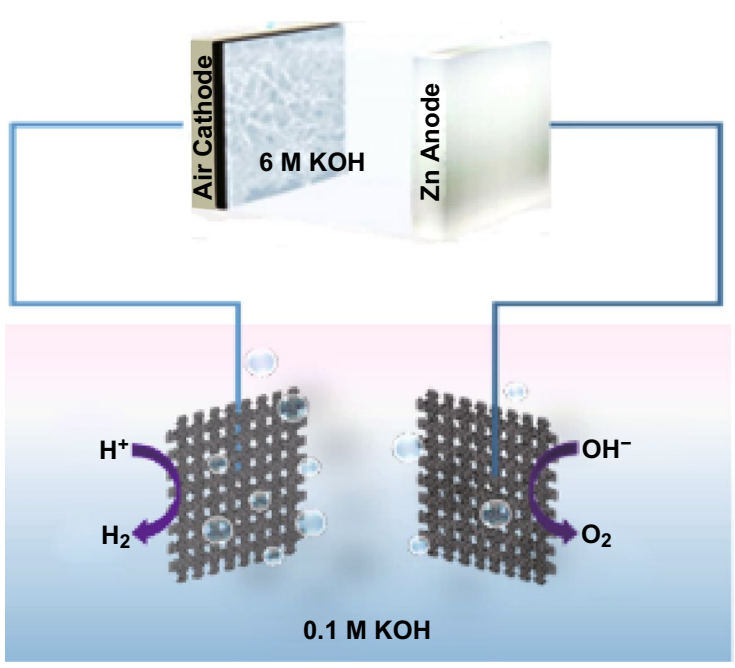


( $842 \mathrm{mAh} \mathrm{g}_{\mathrm{Zn}}^{-1}$ at $5 \mathrm{~mA} \mathrm{~cm}^{-2}$ ), and excellent cycling stability (480 h). Interestingly, the (Ni,Co) $\mathrm{S}_{2}$-based Zn-air battery can efficiently power an electrochemical water-splitting unit with $(\mathrm{Ni}, \mathrm{Co}) \mathrm{S}_{2}$ serving as both the electrodes. This reveals that the prepared $(\mathrm{Ni}, \mathrm{Co}) \mathrm{S}_{2}$ has promising applications in future energy conversion and energy storage devices.

KEYWORDS (Ni,Co)S 2 nanosheet arrays; DFT calculations; Zn-air batteries; Water splitting

\section{Introduction}

The ever-worsening environmental issues and non-renewability of fossil fuels have stimulated extensive investigations for the development of sustainable energy in future energy conversion and storage technology [1-3]. The high-rate oxygen reduction or evolution reaction (ORR or OER) and hydrogen evolution reaction (HER) at lower overpotentials are of great importance to the enhancement of energy utilization rate and output power in these green energy systems. At present, the bottleneck of both water-splitting technologies and rechargeable metal-air batteries is the availability of highly efficient and durable electrocatalysts. Zn-air batteries have the merits of high theoretical energy density, environmental friendliness, and high safety for the next-generation energy storage systems $[4,5]$, where its development is still hampered by a low working voltage owing to the sluggish rate of ORR/OER [6, 7]. Here, HER, which is a crucial electrochemical reaction in water splitting and requires highly efficient electrocatalysts, is equally important $[8,9]$. Pt-based materials exhibit excellent catalytic efficiency for HER and ORR, while Ru- and Ir-based materials are the best electrocatalysts for OER reactions [10-12]. However, their high scarcity, high cost, and insufficient long-term stability are limiting the large-scale commercial applications [13, 14]. Therefore, earth-abundant, durable, and highly efficient trifunctional (ORR, OER, and HER) electrocatalysts are urgently required $[15,16]$.

As a class of low-cost alternatives, transition metalbased materials, such as transition metal phosphides [17, 18], oxides [19-21], sulfides [22, 23], selenides [24, 25], nitrides [26, 27], borides [28, 29], hydroxides [30, 31], and others [32-34], have attracted overwhelming research interests recently. In particular, transition metal sulfides, such as $\mathrm{CoS}_{2}$ and $\mathrm{NiS}_{2}$, are considered a group of low-cost and eco-friendly electrocatalysts for ORR, OER, and HER owing to their high electrocatalytic activity, high stability, and costeffectiveness [35-37]. Substitution of the transition metals with other dopants (such as $\mathrm{V}, \mathrm{Mn}$, and $\mathrm{Cu}$ ) has been proved to enhance their electrocatalytic performance because of the synergistic effects among the metallic atoms [38-40]. Caban-Acevedo et al. [41] recently demonstrated that the replacement of $\mathrm{S}$ atom by $\mathrm{P}$ atom in $\mathrm{CoS}_{2}$, forming CoPS, could alter the electronic structure and dramatically enhance the HER performance. Liang et al. [42] also revealed that their bimetallic NiCoP nanostructures show superior catalytic activity toward both HER and OER in alkaline media compared to monometallic $\mathrm{Ni}_{2} \mathrm{P}$. Although similar efforts are expected to be made for the bimetallic $\mathrm{NiCoS}$, compared with the monometallic counterparts, challenges exist in the design of multifunctional catalysts.

As is known, both $\mathrm{CoS}_{2}$ and $\mathrm{NiS}_{2}$ have the same crystal structure, and the chemical nature and atomic radius of $\mathrm{Ni}$ and Co atoms are very similar, which would enable the formation of bimetallic NiCoS. In this work, we present a detailed study on the synthesis of single-phase bimetallic nickel cobalt sulfide (denoted as $(\mathrm{Ni}, \mathrm{Co}) \mathrm{S}_{2}$ ) nanosheets by the hydrothermal process and subsequent post-sulfuration. The resulting $(\mathrm{Ni}, \mathrm{Co}) \mathrm{S}_{2}$ shows the desired trifunctional electrocatalytic activities in OER, ORR, and HER as an electrocatalyst, and therefore has promising potential as a cathode in $\mathrm{Zn}$-air batteries and water-splitting catalysis. In addition, it demonstrates excellent OER activity with an overpotential of $270 \mathrm{mV}$ at $10 \mathrm{~mA} \mathrm{~cm}{ }^{-2}$ and a notable outstanding potential difference $\left(\Delta E=E_{j=10}-E_{1 / 2}\right)$ between $E_{1 / 2}$ for ORR and $E_{j=10}$ for OER of only $0.79 \mathrm{~V}$, thus outperforming many of the bifunctional electrocatalysts. The air electrode made of $(\mathrm{Ni}, \mathrm{Co}) \mathrm{S}_{2}$ nanosheets exhibited superior performance in both primary and rechargeable $\mathrm{Zn}$-air batteries, showing a specific capacity of $842 \mathrm{mAh} \mathrm{g}_{\mathrm{Zn}}^{-1}$ at $5 \mathrm{~mA} \mathrm{~cm}^{-2}$, a high and stable open circuit potential of $1.48 \mathrm{~V}$, a large peak power density of $152.70 \mathrm{~mW} \mathrm{~cm}^{-2}$, and excellent cycling stability without any decrease in polarization even after $480 \mathrm{~h}$. The rechargeable $\mathrm{Zn}$-air batteries using $(\mathrm{Ni}, \mathrm{Co}) \mathrm{S}_{2}$ as the cathode could efficiently power an electrochemical water-splitting unit catalyzed by the $(\mathrm{Ni}, \mathrm{Co}) \mathrm{S}_{2}$ nanosheets grown on a carbon cloth for both OER and HER, thus demonstrating its potential as an integrated green energy system. 


\section{Experimental}

\subsection{Synthesis of $\mathrm{NiS}_{2}, \mathrm{CoS}_{2}$, and $(\mathrm{Ni}, \mathrm{Co}) \mathrm{S}_{2}$}

\subsubsection{Preparation of Precursors}

Precursors for $(\mathrm{Ni}, \mathrm{Co}) \mathrm{S}_{2}$ were synthesized on a carbon cloth by modifying a reported procedure [39]. First, $1.5 \mathrm{mmol}$ $\mathrm{NiCl}_{2} \cdot 6 \mathrm{H}_{2} \mathrm{O}, 3.0 \mathrm{mmol} \mathrm{NH}_{4} \mathrm{~F}, 7.5 \mathrm{mmol}\left(\mathrm{NH}_{2}\right)_{2} \mathrm{CO}$, and $1.5 \mathrm{mmol} \mathrm{Co}\left(\mathrm{NO}_{3}\right)_{2} \cdot 6 \mathrm{H}_{2} \mathrm{O}$ were dissolved in $50 \mathrm{~mL}$ deionized water. Then, $16 \mathrm{~mL}$ of the solution was transferred to a $23 \mathrm{~mL}$ PTFE-lined stainless steel autoclave containing the substrate leaning against the autoclave wall. The sealed autoclave was heated at $110{ }^{\circ} \mathrm{C}$ for $5 \mathrm{~h}$. After cooling, the substrate was taken out, washed with water and ethanol, and dried in an oven at $60{ }^{\circ} \mathrm{C}$ for $30 \mathrm{~min}$. The precursor of $\mathrm{NiS}_{2}$ or $\mathrm{CoS}_{2}$ was prepared by the same above-mentioned process, except without the addition of $\mathrm{Co}\left(\mathrm{NO}_{3}\right)_{2} \cdot 6 \mathrm{H}_{2} \mathrm{O}$ or $\mathrm{NiCl}_{2} \cdot 6 \mathrm{H}_{2} \mathrm{O}$, respectively.

\subsubsection{Thermal Conversion}

A carbon cloth covered with the as-grown precursor was placed in the center of a fused silica tube in a tube furnace equipped with gas flow controllers. An alumina boat containing $10 \mathrm{mmol}$ of sulfur powder was placed at the furthest upstream position within the reactor tube. The tube was then purged three times with argon gas and maintained at $101.3 \mathrm{kPa}$ under a steady flow of Ar carrier gas (99.999\%) at $25 \mathrm{sccm}$ (standard cubic centimeter per minute). The temperature of the furnace was ramped to $500{ }^{\circ} \mathrm{C}$ and held for $60 \mathrm{~min}$. After cooling under Ar flow, the sample was removed and rinsed with $\mathrm{CS}_{2}(99.9 \%)$ for $10 \mathrm{~min}$, then washed with ethanol, and dried in an oven at $60{ }^{\circ} \mathrm{C}$ for $1 \mathrm{~h}$.

\subsection{Preparation of Electrocatalyst Ink}

The catalyst ink was typically made by dispersing $10 \mathrm{mg}$ of the catalyst and $10 \mathrm{mg}$ of carbon black (Vulcan XC72) in $50 \mathrm{~mL}$ petroleum ether, and then dropped them on a carbon cloth. After drying, $18 \mathrm{mg}$ of catalyst, $90 \mu \mathrm{L}$ Nafion-117

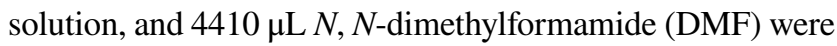
added into a $10 \mathrm{~mL}$ container and ultrasonicated for $30 \mathrm{~min}$.

\subsection{Calculation Details}

The DFT calculations were performed by Vienna ab initio simulation package (VASP). The standard generalizedgradient approximation (GGA) in the form of the Perdew-Burke-Ernzerhof (PBE) exchange model was used. The energy cutoff for the plane-wave basis set and the convergence threshold to obtain the wave functions were 400 and $10^{-5} \mathrm{eV}$, respectively. Further, $3 d$ electrons of $\mathrm{Ni}$ were treated using the GGA $+U$ method with a $U_{\text {eff }}(U-J)$ of $5.76 \mathrm{eV}$. Ionic relaxations were conducted until all the force components became $<0.02 \mathrm{eV} \AA^{-1}$. For the density of states (DOS), the Brillouin zone is represented by the set of $5 \times 5 \times 5 \mathrm{k}$ points for geometry optimizations. A rectangular supercell of size $11.00 \times 11.00 \AA^{2}$ was used to calculate the OER activity with active sites on the (100) surface.

\section{Results and Discussion}

The phase structure of each sample was measured by X-ray diffraction (XRD). As shown in Fig. 1a, the XRD patterns of both $\mathrm{NiS}_{2}$ and $\mathrm{CoS}_{2}$, which were fabricated as reference samples, correspond to a cubic structure with a $\mathrm{Pa}-3$ space group (JCPDS No. 11-0099 for $\mathrm{NiS}_{2}$ and No. 41-1471 for $\mathrm{CoS}_{2}$ ) with lattice constants of $a=b=c=5.567 \AA$ and $a=b=c=5.538 \AA$, respectively. The XRD pattern of $(\mathrm{Ni}, \mathrm{Co}) \mathrm{S}_{2}$ is consistent with those of $\mathrm{NiS}_{2}$ and $\mathrm{CoS}_{2}$ with its diffraction peaks located between those of $\mathrm{NiS}_{2}$ and $\mathrm{CoS}_{2}$, which can be clearly seen from the magnified area of the XRD pattern with the $2 \theta$ angles ranging from $30.5^{\circ}$ to $33.5^{\circ}$ (Fig. 1b). This confirms the formation of a singlephase crystal structure, where $\mathrm{Co}$ and $\mathrm{Ni}$ are alloyed in the bimetallic compound structure. Raman spectroscopy was employed to further confirm the formation of single-phase $(\mathrm{Ni}, \mathrm{Co}) \mathrm{S}_{2}$. For the monometallic samples, distinct peaks are observed at about $479 \mathrm{~cm}^{-1}$ for $\mathrm{NiS}_{2}$ and $391 \mathrm{~cm}^{-1}$ for $\mathrm{CoS}_{2}$ corresponding to the out-of-plane $A_{\mathrm{g}}$ vibrational mode (Fig. 1c) [43, 44]. For $(\mathrm{Ni}, \mathrm{Co}) \mathrm{S}_{2}$, the peak of $A_{\mathrm{g}}$ vibrational mode is located at $425 \mathrm{~cm}^{-1}$ between those of $\mathrm{NiS}_{2}$ and $\mathrm{CoS}_{2}$, indicating that the atomic vibration in $(\mathrm{Ni}, \mathrm{Co}) \mathrm{S}_{2}$ is a unified whole; this concurs with the XRD result. In addition, an obvious peak at $276 \mathrm{~cm}^{-1}$ is observed for all the three samples, which corresponds to the in-plane vibration mode of $E_{\mathrm{g}}$ for the cubic structure [45, 46]. The morphology was studied by both scanning electron microscopy (SEM) 
and transmission electron microscopy (TEM). Figure 1d shows that the as-synthesized $(\mathrm{Ni}, \mathrm{Co}) \mathrm{S}_{2}$ has the morphology of cactus-like nanosheets growing uniformly on the carbon cloth, which are nanoplates with some nanowires at the edges. It is not a combination of two morphologies but is a single morphology, which can be confirmed by subsequent high-resolution TEM (HRTEM) analysis. In contrast, $\mathrm{NiS}_{2}$ has nanoplate morphology, while $\mathrm{CoS}_{2}$ has nanowire morphology with a diameter of 50-100 nm (Fig. S1). The TEM images shown in Fig. 1e further confirm the formation of the observed nanosheet morphology with nanowires grown at the edges. Figure 1f, h shows the HRTEM images of the nanosheet and nanowire regions of $(\mathrm{Ni}, \mathrm{Co}) \mathrm{S}_{2}$, where lattices with spacings of 2.79 and $2.50 \AA$ can be assigned to the (200) and (210) planes of $(\mathrm{Ni}, \mathrm{Co}) \mathrm{S}_{2}$, respectively. These lattice spacing values are between those of $\mathrm{NiS}_{2}$ and $\mathrm{CoS}_{2}$ (Fig. S2), which further reveals that $(\mathrm{Ni}, \mathrm{Co}) \mathrm{S}_{2}$ is a singlephase structure. The energy-dispersive $\mathrm{X}$-ray spectrum (EDS) shows that $(\mathrm{Ni}, \mathrm{Co}) \mathrm{S}_{2}$ has a $\mathrm{Ni} / \mathrm{Co}$ atomic ratio of 1:1 (Fig. 1g). The element mapping images in Fig. 1i show that $\mathrm{Ni}, \mathrm{Co}$, and $\mathrm{S}$ elements are uniformly distributed in the selected area.

To further examine their composition and valence state, X-ray photoelectron spectroscopy (XPS) measurements were performed. The wide spectrum of $(\mathrm{Ni}, \mathrm{Co}) \mathrm{S}_{2}$ reveals the presence of $\mathrm{Ni}, \mathrm{Co}$, and $\mathrm{S}$ elements (Fig. S3). The Co (a)
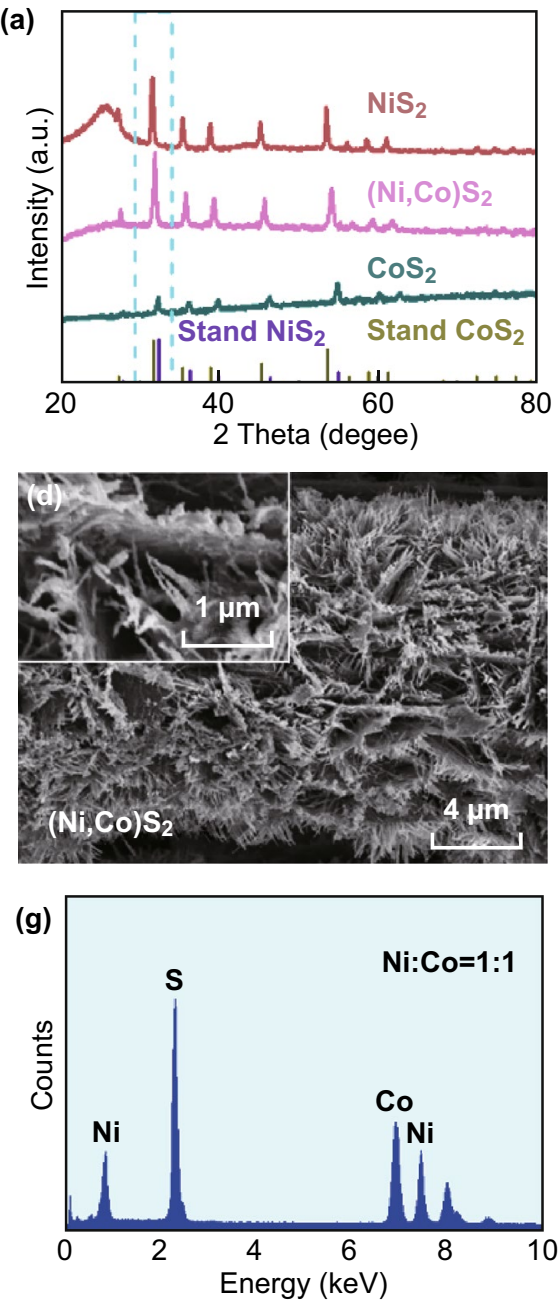

(b)
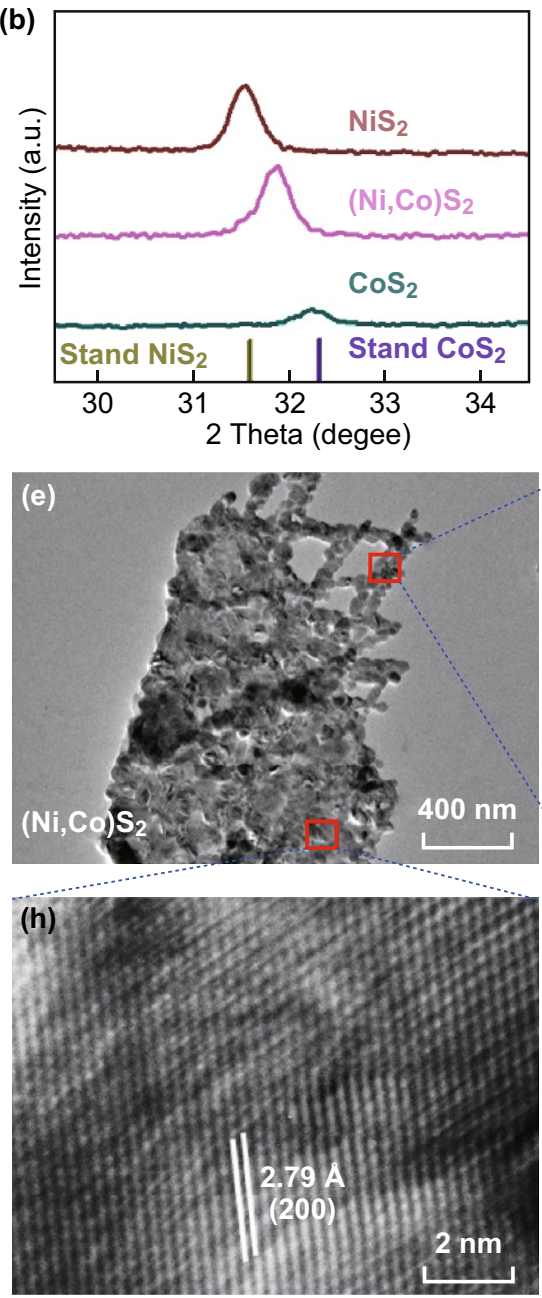

(c)
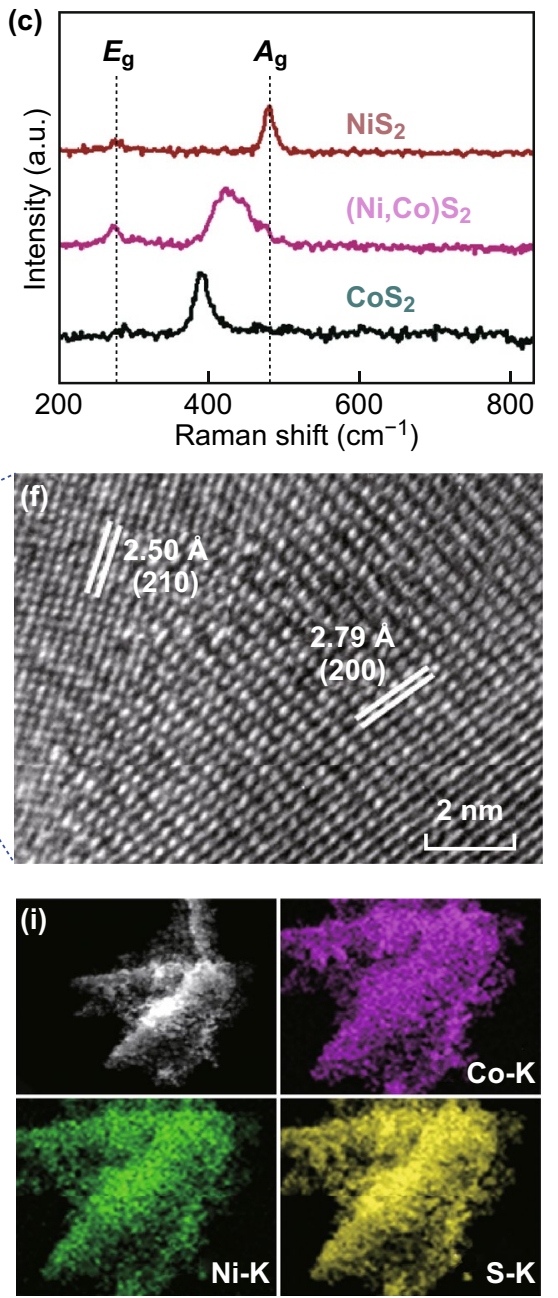

Fig. 1 a XRD spectra of $(\mathrm{Ni}, \mathrm{Co}) \mathrm{S}_{2}, \mathrm{NiS}_{2}$, and $\mathrm{CoS}_{2}$. b High-resolution XRD spectra with 2 theta angles ranging from $30.5^{\circ}$ to $33.5^{\circ}$. $\mathbf{c}$ Raman spectra of $(\mathrm{Ni}, \mathrm{Co}) \mathrm{S}_{2}, \mathrm{NiS}_{2}$, and $\mathrm{CoS}_{2}$. d SEM image of $(\mathrm{Ni}, \mathrm{Co}) \mathrm{S}_{2}$. The insert is high-magnification SEM image. e TEM image, $\mathbf{f}, \mathbf{h}$ HRTEM images, and $\mathbf{g}$ EDS spectrum of $(\mathrm{Ni}, \mathrm{Co}) \mathrm{S}_{2}$. i EDS mapping images of $\mathrm{Ni}, \mathrm{Co}$, and $\mathrm{S}$ elements in $(\mathrm{Ni}, \mathrm{Co}) \mathrm{S}_{2}$ 
$2 p$ spectrum in Fig. 2 a shows the main peaks of Co $2 p_{3 / 2}$ and Co $2 p_{1 / 2}$ along with their satellite peaks. For $\mathrm{CoS}_{2}$ and $(\mathrm{Ni}, \mathrm{Co}) \mathrm{S}_{2}$, two peaks appear at 778.5 and $781.6 \mathrm{eV}$, which belong to $\mathrm{Co} 2 p_{3 / 2}$ and indicate the presence of $\mathrm{Co}^{2+}$ [47]. The Ni $2 p$ spectrum (Fig. $2 \mathrm{~b}$ ) shows $2 p_{3 / 2}$ and $2 p_{1 / 2}$ doublets due to spin-orbit coupling. The $\mathrm{Ni} 2 p$ spectra of both $\mathrm{NiS}_{2}$ and $(\mathrm{Ni}, \mathrm{Co}) \mathrm{S}_{2}$ show two peaks at 854.7 and $856.3 \mathrm{eV}$ corresponding to $\mathrm{Ni} 2 p_{3 / 2}$, and a satellite peak at higher binding energies [48]. The $\mathrm{S} 2 p_{1 / 2}$ and $\mathrm{S} 2 p_{3 / 2}$ peaks for these three samples are located at 164.1 and $162.8 \mathrm{eV}$, respectively, corresponding to $\left(\mathrm{S}_{2}\right)^{2-}$ (Fig. 2c) [49]. The binding energies of $\mathrm{Ni} 2 p$ and $\mathrm{Co} 2 p$ in $(\mathrm{Ni}, \mathrm{Co}) \mathrm{S}_{2}$ show no obvious shift compared with $\mathrm{NiS}_{2}$ and $\mathrm{CoS}_{2}$, revealing that the $\mathrm{Ni}$ and $\mathrm{Co}$ atoms are uniformly distributed in the crystal structure. Thus, we demonstrated the formation of single-phase $(\mathrm{Ni}, \mathrm{Co}) \mathrm{S}_{2}$ in our case. Figure $2 \mathrm{~d}$ shows the calculated DOS of $(\mathrm{Ni}, \mathrm{Co}) \mathrm{S}_{2}, \mathrm{NiS}_{2}$, and $\mathrm{CoS}_{2}$. It can be seen that $(\mathrm{Ni}, \mathrm{Co}) \mathrm{S}_{2}$ shows metallic nature with more electron-occupied states at the Fermi level, while $\mathrm{CoS}_{2}$ shows metallicity and $\mathrm{NiS}_{2}$ shows semiconductor characteristic (bandgap $=0.6 \mathrm{eV}$ ). As shown by the schematic in Fig. S4 and the inset of Fig. 2e,
$(\mathrm{Ni}, \mathrm{Co}) \mathrm{S}_{2}$ has a cubic crystal structure, with $\mathrm{Ni}$ atoms replacing half of the Co atoms, adopting the $\mathrm{CoS}_{2}$ structure. The partial density of states (PDOS) curves of $(\mathrm{Ni}, \mathrm{Co}) \mathrm{S}_{2}$ shown in Fig. 2e indicate a strong hybridization of $\mathrm{Ni} 3 d$, Co $3 d$, and $\mathrm{S} 2 p$, which combined with the charge density distribution results (Fig. 2f), suggest an outstanding electrical conductivity of $(\mathrm{Ni}, \mathrm{Co}) \mathrm{S}_{2}$. The PDOS of $\mathrm{NiS}_{2}$ and $\mathrm{CoS}_{2}$ are shown in the supporting information for comparison (Figs. S5, S6).

The performance of $(\mathrm{Ni}, \mathrm{Co}) \mathrm{S}_{2}$ in electrocatalytic oxygen evolution is evaluated using a three-electrode configuration in $0.1 \mathrm{M} \mathrm{KOH}$ solution, where $\mathrm{NiS}_{2}, \mathrm{CoS}_{2}$, and commercial $\mathrm{Ir} / \mathrm{C}$ catalysts are used as the control samples. The polarization curve is firstly obtained by linear voltammetry scanning (LSV). The original LSV curves for OER are shown in the supporting information (Fig. S7). After converting by the method detailed in the supporting information, the standard polarization curves are obtained. As shown in Fig. 3a, the onset overpotential of $(\mathrm{Ni}, \mathrm{Co}) \mathrm{S}_{2}$ is $1.47 \mathrm{~V}$, which is lower than that of $\mathrm{NiS}_{2}(1.57 \mathrm{~V}), \mathrm{CoS}_{2}(1.50 \mathrm{~V})$, and commercial $\mathrm{Ir} / \mathrm{C}(1.48 \mathrm{~V})$. For $\mathrm{NiS}_{2}$ and $(\mathrm{Ni}, \mathrm{Co}) \mathrm{S}_{2}$, there is a
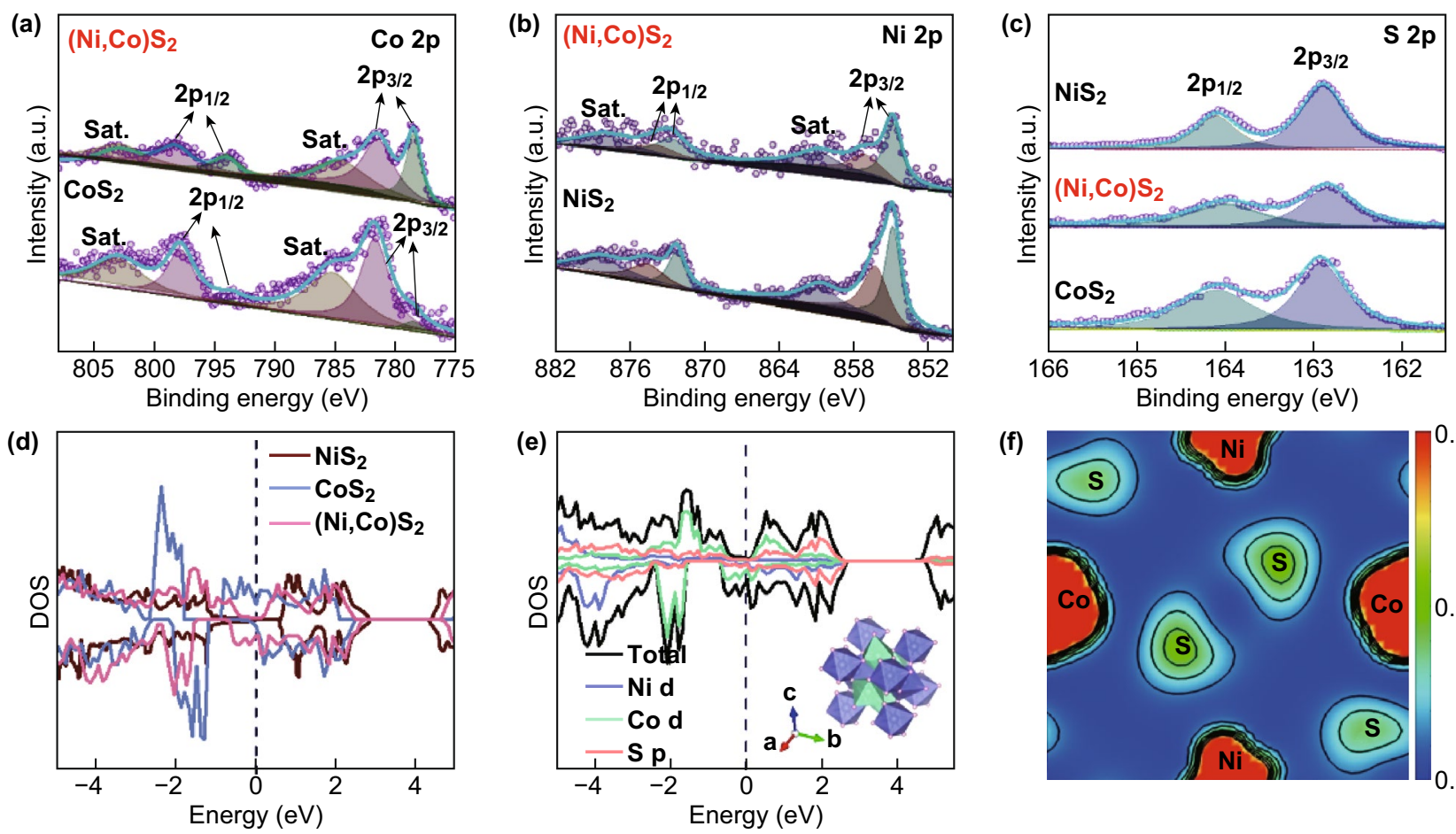

(f)

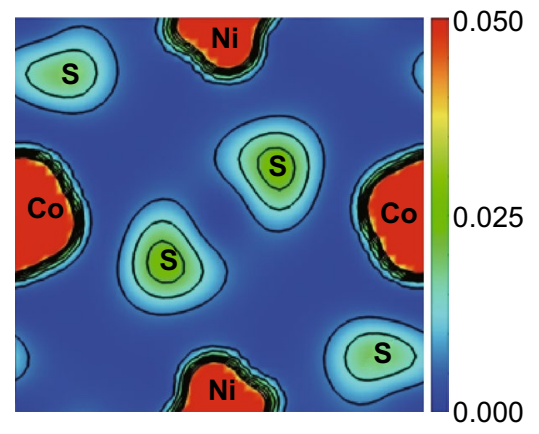

Fig. 2 High-resolution XPS spectra of a Co $2 p$, b Ni $2 p$, and c S $2 p$. d Density of states (DOS) curves of $\left(\mathrm{Ni}_{1} \mathrm{Co}\right) \mathrm{S}_{2}$, NiS $\mathrm{N}_{2}$, and CoS 2 e Partial density of states (PDOS) curves of $(\mathrm{Ni}, \mathrm{Co}) \mathrm{S}_{2}$. Insert shows the optimized crystal structure of $(\mathrm{Ni}, \mathrm{Co}) \mathrm{S}_{2}$. f Charge density distribution of $(\mathrm{Ni}, \mathrm{Co})$ $\mathrm{S}_{2}$ 
visible oxidation peak at about $1.32 \mathrm{~V}$, which is similar to that previously reported for Ni-based catalysts [48]. Upon deducting the thermodynamic water decomposition voltage of $1.23 \mathrm{~V}$ [50], $(\mathrm{Ni}, \mathrm{Co}) \mathrm{S}_{2}$ shows an initial overpotential of $240 \mathrm{mV}$. When the current density reaches $10 \mathrm{~mA} \mathrm{~cm}^{-2}$, the overpotential of $(\mathrm{Ni}, \mathrm{Co}) \mathrm{S}_{2}$ is $270 \mathrm{mV}$ and compares favorably to 410,350 , and $310 \mathrm{mV}$ for $\mathrm{NiS}_{2}, \mathrm{CoS}_{2}$, and $\mathrm{Ir} / \mathrm{C}$, respectively. As shown in Fig. 3b, the Tafel slope of $(\mathrm{Ni}, \mathrm{Co}) \mathrm{S}_{2}$ is $58 \mathrm{mV} \mathrm{dec}^{-1}$, which is smaller than that of $\mathrm{NiS}_{2}$ $\left(123 \mathrm{mV} \mathrm{dec}^{-1}\right)$ and $\mathrm{CoS}_{2}\left(107 \mathrm{mV} \mathrm{dec}^{-1}\right)$ and is close to that of $\mathrm{Ir} / \mathrm{C}\left(77 \mathrm{mV} \mathrm{dec}^{-1}\right)$. The reduced Tafel slope indicates that $(\mathrm{Ni}, \mathrm{Co}) \mathrm{S}_{2}$ exhibits a faster dynamics in the OER process [51]. Electrochemical impedance spectroscopy (EIS) was further employed to understand the interfacial electron transport between the electrolyte and catalyst at $1.45 \mathrm{~V}$ versus RHE from $10 \mathrm{kHz}$ to $0.1 \mathrm{~Hz}$. The curve fitting and equivalent circuit analysis results of the EIS data agree well with the (RQR) model. In Fig. $3 \mathrm{c}, R_{\mathrm{s}}$ is the solution resistance $(\sim 3 \Omega)$ and $R_{\mathrm{ct}}$ is the charge transfer resistance. A lower $R_{\mathrm{ct}}$ corresponds to a faster electronic transmission [52]. As illustrated in Fig. 3c, the EIS of $(\mathrm{Ni}, \mathrm{Co}) \mathrm{S}_{2}$ shows the smallest radius corresponding to the minimum $R_{\mathrm{ct}}$ value and indicates a faster reaction rate than those of $\mathrm{NiS}_{2}$ and $\mathrm{CoS}_{2}$. The double-layer capacitance $\left(C_{\mathrm{dl}}\right)$ is obtained by cyclic voltammetry $(\mathrm{CV})$ performed at different scan rates (in the range of $20-180 \mathrm{mV} \mathrm{s}^{-1}$, Fig. S8) to evaluate the electrochemical
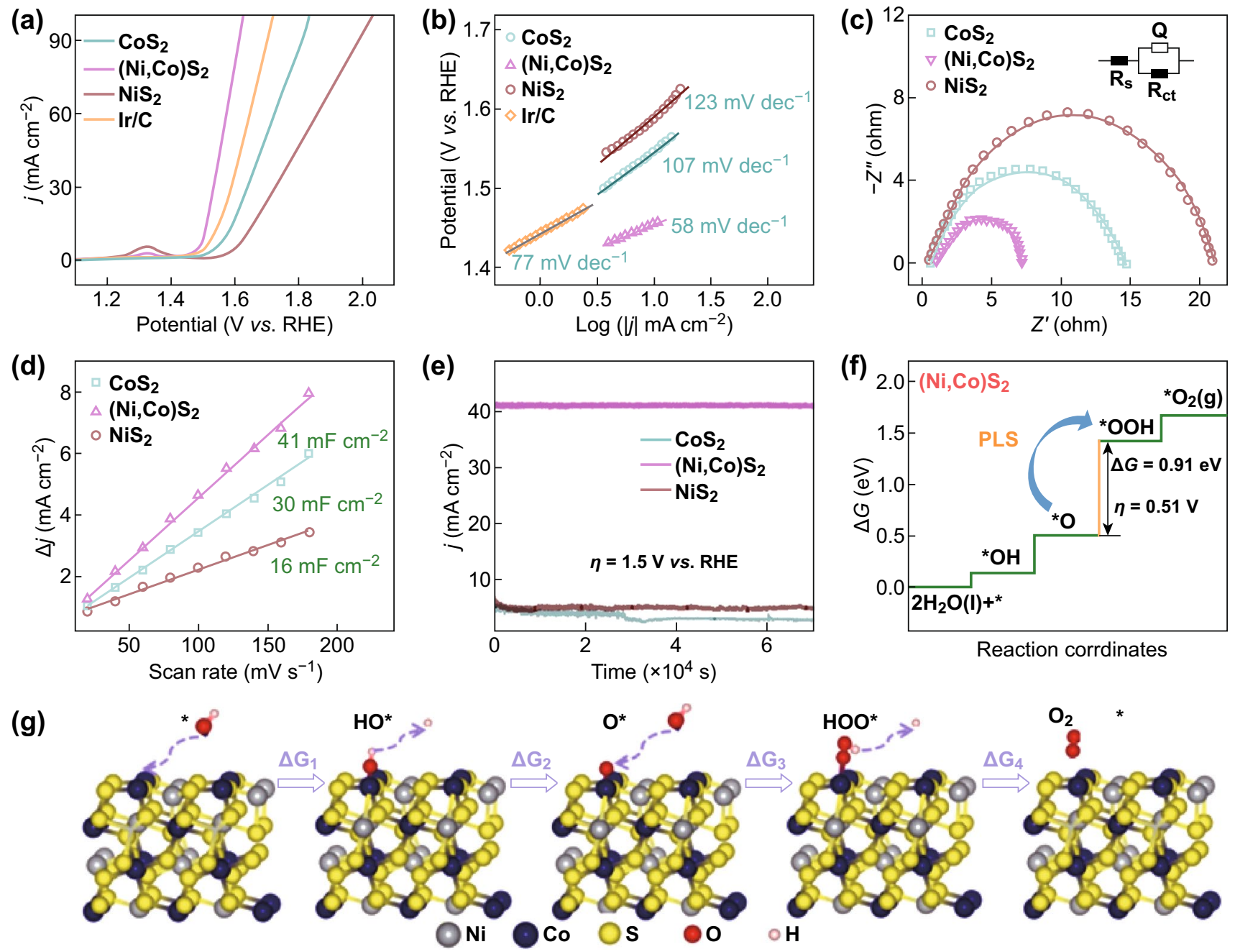

Fig. 3 a Polarization curves of $(\mathrm{Ni}, \mathrm{Co}) \mathrm{S}_{2}, \mathrm{NiS}_{2}, \mathrm{CoS}_{2}$, and $\mathrm{Ir} / \mathrm{C}(20 \% \mathrm{Ir})$ at $5 \mathrm{mV} \mathrm{s}{ }^{-1}$ in $0.1 \mathrm{M} \mathrm{KOH}$. b Tafel slopes obtained from the corresponding polarization curves. c EIS of $(\mathrm{Ni}, \mathrm{Co}) \mathrm{S}_{2}, \mathrm{NiS}_{2}$, and $\mathrm{CoS}_{2}$. The inset is an analogue circuit diagram. d $C_{\mathrm{dl}}$ obtained by cyclic voltammetry at different scan rates. e $I-t$ curves at $1.5 \mathrm{~V}$ versus RHE for $7 \times 10^{4} \mathrm{~s}$. f Schematic of Gibbs free energy changes in the four elementary steps during OER on (100) surface of $(\mathrm{Ni}, \mathrm{Co}) \mathrm{S}_{2}$. g Proposed 4-step OER path presented using the model of (100) surface of $(\mathrm{Ni}, \mathrm{Co}) \mathrm{S}_{2}$ 
active sites [53]. Figure $3 \mathrm{~d}$ shows that the $C_{\mathrm{dl}}$ of $(\mathrm{Ni}, \mathrm{Co})$ $\mathrm{S}_{2}$ is $41 \mathrm{mF} \mathrm{cm}^{-2}$, which is larger than the $C_{\mathrm{dl}}$ of $\mathrm{CoS}_{2}$ $\left(30 \mathrm{mF} \mathrm{cm}^{-2}\right)$ and two times the $C_{\mathrm{dl}}$ of $\mathrm{NiS}_{2}\left(16 \mathrm{mF} \mathrm{cm}^{-2}\right)$; this reveals that there are more electrochemical active sites in $(\mathrm{Ni}, \mathrm{Co}) \mathrm{S}_{2}$ for OER. The synergistic effect of $\mathrm{Ni}$ and $\mathrm{Co}$ in $(\mathrm{Ni}, \mathrm{Co}) \mathrm{S}_{2}$ activates new active sites, increasing the electrochemical active surface area (EASA). To further assess the OER catalytic rates, the turnover frequencies (TOFs) of the three electrocatalysts were estimated, assuming that all the metal ions in the electrocatalysts were catalytically active (Fig. S9) [54]. As shown in Fig. S9, at an overpotential of $1.55 \mathrm{~V}$ versus RHE, the TOF of $(\mathrm{Ni}, \mathrm{Co}) \mathrm{S}_{2}$ is $3.02 \mathrm{~s}^{-1}$, whereas the TOFs of $\mathrm{CoS}_{2}$ and $\mathrm{NiS}_{2}$ are 0.65 and $0.22 \mathrm{~s}^{-1}$, respectively. This suggests that $(\mathrm{Ni}, \mathrm{Co}) \mathrm{S}_{2}$ has the fastest rate for OER catalysis. The OER parameters of the three catalysts and $\mathrm{Ir} / \mathrm{C}$ are listed in Table $\mathrm{S} 1$ for comparison. As shown in Fig. 3e, even after testing for 70,000 s at $1.5 \mathrm{~V}$, the current density of $(\mathrm{Ni}, \mathrm{Co}) \mathrm{S}_{2}$ remains at $40 \mathrm{~mA} \mathrm{~cm}^{-2}$, revealing the outstanding stability of $(\mathrm{Ni}, \mathrm{Co}) \mathrm{S}_{2}$ in OER compared with the degenerated current densities of $\mathrm{NiS}_{2}$ and $\mathrm{CoS}_{2}$. A comparison of the OER performance of $(\mathrm{Ni}, \mathrm{Co}) \mathrm{S}_{2}$ with that of other typical catalysts is shown in Table S2. For comparison, the OER polarization curves of the physically mixed $\mathrm{CoS}_{2}$ and $\mathrm{NiS}_{2}$ (named $\mathrm{CoS}_{2}+\mathrm{NiS}_{2}$ ) were also examined, which reveals that its performance is in between those of $\mathrm{CoS}_{2}$ and $\mathrm{NiS}_{2}$ (Fig. S10). Besides, the structure and morphology after the long cycling test and the structural evolution process are shown in Figs. S11-13. The diffraction peaks of the cycled $(\mathrm{Ni}, \mathrm{Co}) \mathrm{S}_{2}$ are similar to those of the fresh $(\mathrm{Ni}, \mathrm{Co}) \mathrm{S}_{2}$, indicating that it retains its phase even after prolonged tests. The surface of the nanosheets is constantly corroded during repeated charge and discharge tests, resulting in a coarse surface and some oxidation state. The entire OER progress can be summarized in four elementary reaction models consisting of three key intermediates: ${ }^{*} \mathrm{OH},{ }^{*} \mathrm{O}$, and ${ }^{*} \mathrm{OOH}$ (Fig. 3g) [55]. Each elementary step releases $\mathrm{H}^{+}$cation and electron. It is crucial for the intermediate to have an appropriate Gibbs free energy. Figure $3 f$ shows the Gibbs free energy $(\Delta G)$ diagram for the (100) surface of $(\mathrm{Ni}, \mathrm{Co}) \mathrm{S}_{2}$ with correlative intermediates at different reaction steps. It can be seen that the third step is the potential limiting step (PLS), where an adsorbed $\mathrm{O}$ atom reacts with a $\mathrm{H}_{2} \mathrm{O}$ molecule to form a $* \mathrm{OOH}$. The overpotential $(\eta)$ calculated by DFT calculations is $0.51 \mathrm{~V}$ for $* \mathrm{O}+\mathrm{H}_{2} \mathrm{O}(\mathrm{l}) \rightleftharpoons * \mathrm{OOH}+\mathrm{H}^{+}+\mathrm{e}^{-}$, which is smaller than that of pure $\operatorname{CoS}_{2}(\eta=0.54 \mathrm{~V})$ and $\mathrm{NiS}_{2}(\eta=2.00 \mathrm{~V})$ at the (001) surface (Figs. S14, S15). The calculated results are consistent with the above experiment results, indicating that bimetallic $(\mathrm{Ni}, \mathrm{Co}) \mathrm{S}_{2}$ can be a better electrocatalyst than monometallic $\mathrm{CoS}_{2}$ and $\mathrm{NiS}_{2}$.

Oxygen reduction activities were studied to determine the suitability of $(\mathrm{Ni}, \mathrm{Co}) \mathrm{S}_{2}$ as a bifunctional electrocatalyst for both ORR and OER. It was examined with a rotating disk electrode (RDE) in $0.1 \mathrm{M}$ aq. $\mathrm{KOH}$ electrolyte at room temperature. As shown in Fig. $4 \mathrm{a},(\mathrm{Ni}, \mathrm{Co}) \mathrm{S}_{2}$ shows the highest onset overpotential of $0.82 \mathrm{~V}$, while it is 0.79 and $0.76 \mathrm{~V}$ for $\mathrm{CoS}_{2}$ and $\mathrm{NiS}_{2}$, respectively. The limiting current densities were measured as $4.2,3.0$, and $3.7 \mathrm{~mA} \mathrm{~cm}^{-2}$ for $(\mathrm{Ni}, \mathrm{Co})$ $\mathrm{S}_{2}, \mathrm{CoS}_{2}$, and $\mathrm{NiS}_{2}$, respectively, at overpotential of $0.20 \mathrm{~V}$. The half-wave potential of $(\mathrm{Ni}, \mathrm{Co}) \mathrm{S}_{2}(0.71 \mathrm{~V})$ is slightly smaller than that of $\mathrm{Pt} / \mathrm{C}(0.78 \mathrm{~V})$ but higher than that of $\mathrm{CoS}_{2}(0.63 \mathrm{~V})$ and $\mathrm{NiS}_{2}(0.68 \mathrm{~V})$. The physically mixed sample $\mathrm{CoS}_{2}+\mathrm{NiS}_{2}$ was also measured. The results show that its ORR performance is between that of $\mathrm{CoS}_{2}$ and $\mathrm{NiS}_{2}$, which illustrates the importance of $(\mathrm{Ni}, \mathrm{Co}) \mathrm{S}_{2}$ as a single-phase bimetallic catalyst (Fig. S16).

The CV scan results are shown in Fig. 4b. The curve measured in a $\mathrm{N}_{2}$-saturated electrolyte solution is smooth, indicating no oxygen reduction reaction. However, in the $\mathrm{O}_{2}$-saturated electrolyte solution, a sharp cathodic peak appeared at $0.75 \mathrm{~V}$, revealing the occurrence of an ORR. Under the same test conditions, the oxygen reduction peaks of $\mathrm{NiS}_{2}$ and $\mathrm{CoS}_{2}$ are 0.74 and $0.67 \mathrm{~V}$, respectively (Fig. S17). To explore the reaction mechanism of oxygen reduction, LSV curves with various speeds (from 400 to $2400 \mathrm{rpm}$ ) were measured, and the results shown in Fig. 4c indicate that the current density increases with increasing $\mathrm{O}_{2}$ diffusion rate. According to the $K-L$ equation [56], the calculated electron transfer number $(n)$ is 3.8 , which indicates that a four-electron process dominates the oxygen reduction for $(\mathrm{Ni}, \mathrm{Co}) \mathrm{S}_{2}$. Table $\mathrm{S} 3$ lists the ORR parameters of the three catalysts. The ORR path was further verified with a rotating ring-disk electrode (RRDE) at $1.3 \mathrm{~V}$ at a rate of $2 \mathrm{mV} \mathrm{s}^{-1}$. As shown in Fig. $4 \mathrm{~d}$, the $n$ value (3.9) thus estimated is consistent with the result obtained from the $K-L$ equation. It clearly indicates that the oxygen reduction proceeds via an efficient four-electron pathway. A comparison of the ORR performance of $(\mathrm{Ni}, \mathrm{Co}) \mathrm{S}_{2}$ with the performances of some of the reported catalysts is shown in Table S4. As a bifunctional electrocatalyst, the overall oxygen activity of $(\mathrm{Ni}, \mathrm{Co}) \mathrm{S}_{2}$ is evaluated by the potential difference $\left(\Delta E=E_{j=10}-E_{1 / 2}\right)$ between $E_{1 / 2}$ for ORR and $E_{j=10}$ for OER. In general, an efficient reversible oxidation 

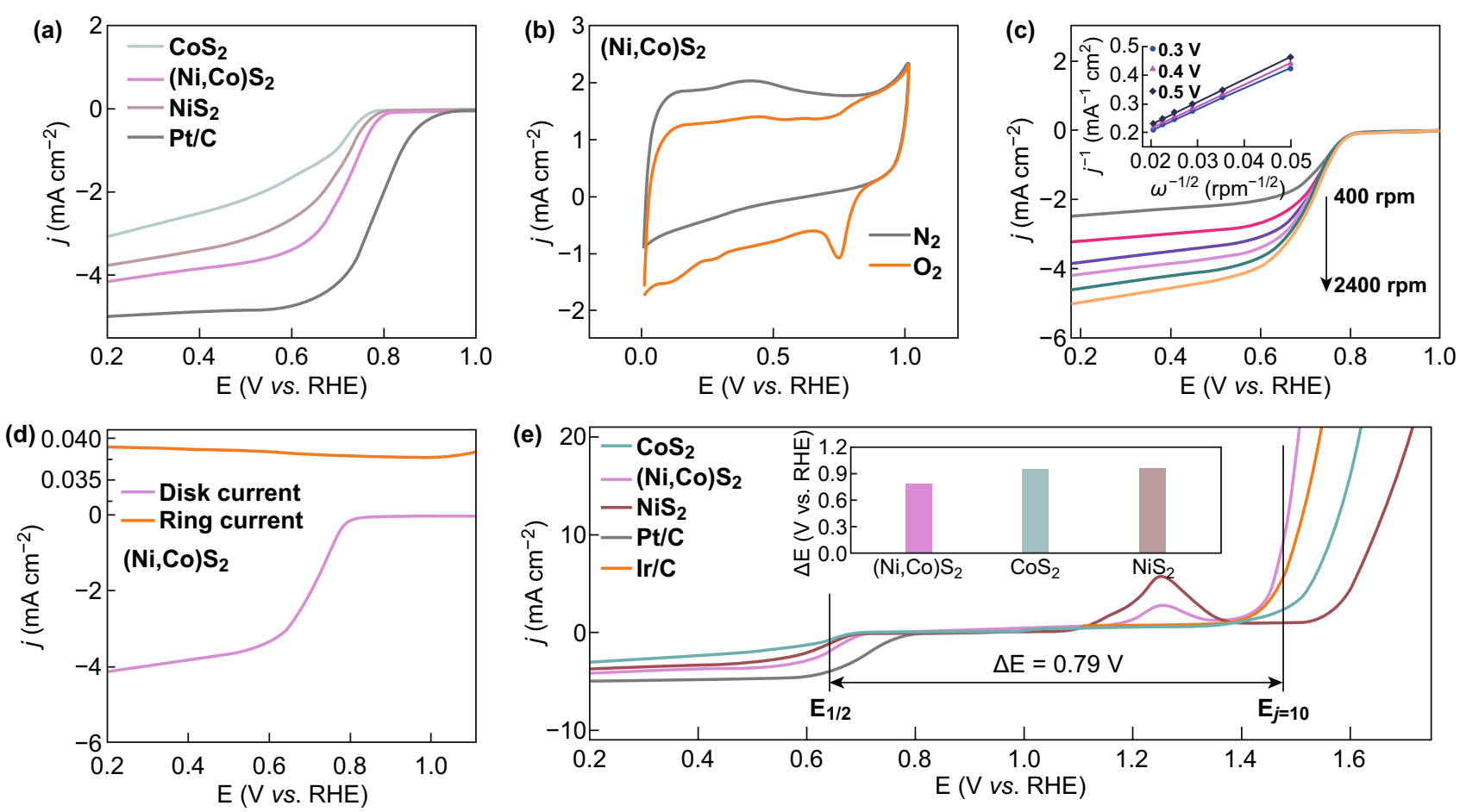

Fig. 4 a ORR polarization curves of $(\mathrm{Ni}, \mathrm{Co}) \mathrm{S}_{2}, \mathrm{NiS}_{2}, \mathrm{CoS}_{2}$, and $\mathrm{Pt} / \mathrm{C}(20 \% \mathrm{Pt})$ at $2 \mathrm{mV} \mathrm{s}^{-1}$ in $0.1 \mathrm{M} \mathrm{KOH}$ at $1600 \mathrm{rpm}$. b CVs of $(\mathrm{Ni}, \mathrm{Co})$ $\mathrm{S}_{2}$ in $\mathrm{O}_{2}$ and $\mathrm{N}_{2}$-saturated $0.1 \mathrm{M} \mathrm{KOH}$ solution. c ORR polarization curves of $(\mathrm{Ni}, \mathrm{Co}) \mathrm{S}_{2}$ at different rotation rates from 400 to $2400 \mathrm{rpm}$. The inset figure is the $K-L$ plots. d RRDE polarization curves of $(\mathrm{Ni}, \mathrm{Co}) \mathrm{S}_{2}$ at $1600 \mathrm{rpm}$. The ring electrode was polarized at $1.5 \mathrm{~V}$ at a scan rate of $2 \mathrm{mV} \mathrm{s}^{-1}$. e Bifunctional electrocatalytic activities of various catalysts toward both ORR and OER

reaction requires a small $\Delta E$, with the $\Delta E$ of commercial state-of-the-art electrocatalysts reported as $0.94 \mathrm{~V}$ for $\mathrm{Pt} / \mathrm{C}$ and $0.92 \mathrm{~V}$ for $\mathrm{Ir} / \mathrm{C}$ and $\mathrm{Ru} / \mathrm{C}$ [57]. Figure $4 \mathrm{e}$ shows that the $\Delta E$ of $(\mathrm{Ni}, \mathrm{Co}) \mathrm{S}_{2}$ is $0.79 \mathrm{~V}$, which is much lower than those of the reported precious electrocatalysts (Table S5) as well as the $\Delta E$ of $\mathrm{NiS}_{2}(0.95 \mathrm{~V})$ and $\mathrm{CoS}_{2}(0.94 \mathrm{~V})$. This further indicates the excellent electrocatalytic characteristics of $(\mathrm{Ni}, \mathrm{Co}) \mathrm{S}_{2}$ as a multifunctional electrocatalyst.

To demonstrate the application potential of $(\mathrm{Ni}, \mathrm{Co}) \mathrm{S}_{2}$ nanosheets as a bifunctional electrocatalyst for a $\mathrm{Zn}$-air battery, we first constructed primary Zn-air batteries by using $(\mathrm{Ni}, \mathrm{Co}) \mathrm{S}_{2}$ as the electrocatalyst. The schematic diagram of a two-electrode liquid rechargeable battery is shown in Fig. 5a. The $(\mathrm{Ni}, \mathrm{Co}) \mathrm{S}_{2}$-based $\mathrm{Zn}$-air battery shows an open cell voltage of $1.48 \mathrm{~V}$ at the beginning (Fig. 5b), which is similar to the result obtained by the multimeter test. After a continuous discharge of $20 \mathrm{~h}$, the discharge voltage of $(\mathrm{Ni}, \mathrm{Co}) \mathrm{S}_{2}$ remains at $1.47 \mathrm{~V}$, which is an ideal and stable high discharge voltage, whereas the open cell voltages of $\mathrm{NiS}_{2}$ - and $\mathrm{CoS}_{2}$-based $\mathrm{Zn}$-air batteries are 1.42 and $1.38 \mathrm{~V}$, respectively (Fig. S18). As shown in Fig. 5c, the battery energy density of $(\mathrm{Ni}, \mathrm{Co}) \mathrm{S}_{2}$-based $\mathrm{Zn}$-air battery is $152.7 \mathrm{~W} \mathrm{~cm}^{-2}$. A current density of $170 \mathrm{~mA} \mathrm{~cm}{ }^{-2}$ was measured at an overpotential of $0.40 \mathrm{~V}$. The charge and discharge cycle tests of $(\mathrm{Ni}, \mathrm{Co}) \mathrm{S}_{2}$-based $\mathrm{Zn}$-air batteries were performed with $20 \mathrm{~min}$ cycles (charging for $10 \mathrm{~min}$ and discharging for $10 \mathrm{~min}$; Fig. 5d). At a current density of $2 \mathrm{~mA} \mathrm{~cm}^{-2}$, it shows a stable charging voltage of $1.71 \mathrm{~V}$ and a discharge voltage $1.26 \mathrm{~V}$ with a very small charge-discharge gap of $0.45 \mathrm{~V}$, which increases to $0.46 \mathrm{~V}$ after $480 \mathrm{~h}$ (Fig. 5e), revealing its superb stability. This value is much higher than that of many of the reported catalysts (Table S6). Similarly, the charge and discharge cycle curves were tested at a current density of $6 \mathrm{~mA} \mathrm{~cm}{ }^{-2}$ for $100 \mathrm{~h}$ (Fig. S19). The results indicate that the $(\mathrm{Ni}, \mathrm{Co}) \mathrm{S}_{2}$-based $\mathrm{Zn}$-air battery has a large specific capacity of $842 \mathrm{mAh} \mathrm{g}_{\mathrm{Zn}}^{-1}$ at a current density of $5 \mathrm{~mA} \mathrm{~cm} \mathrm{c}^{-2}$ (Fig. 5f), which is larger than that of both $\mathrm{NiS}_{2}\left(732 \mathrm{mAh} \mathrm{g}_{\mathrm{Zn}}^{-1}\right)$ and $\mathrm{CoS}_{2}\left(681 \mathrm{mAh} \mathrm{g}_{\mathrm{Zn}}^{-1}\right)$ (Fig. S20). Besides, two liquid zinc-air batteries in series could power a red LED (Fig. 5g), while one liquid zinc-air battery could power an electronic watch successfully (Fig. 5h). 
(a)

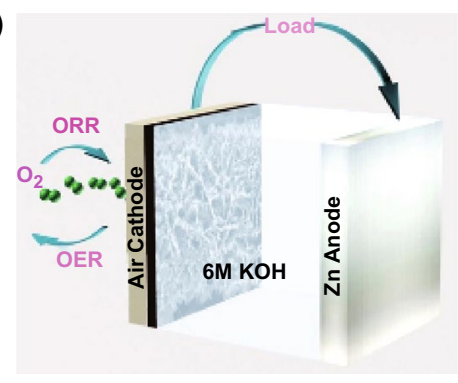

(d)
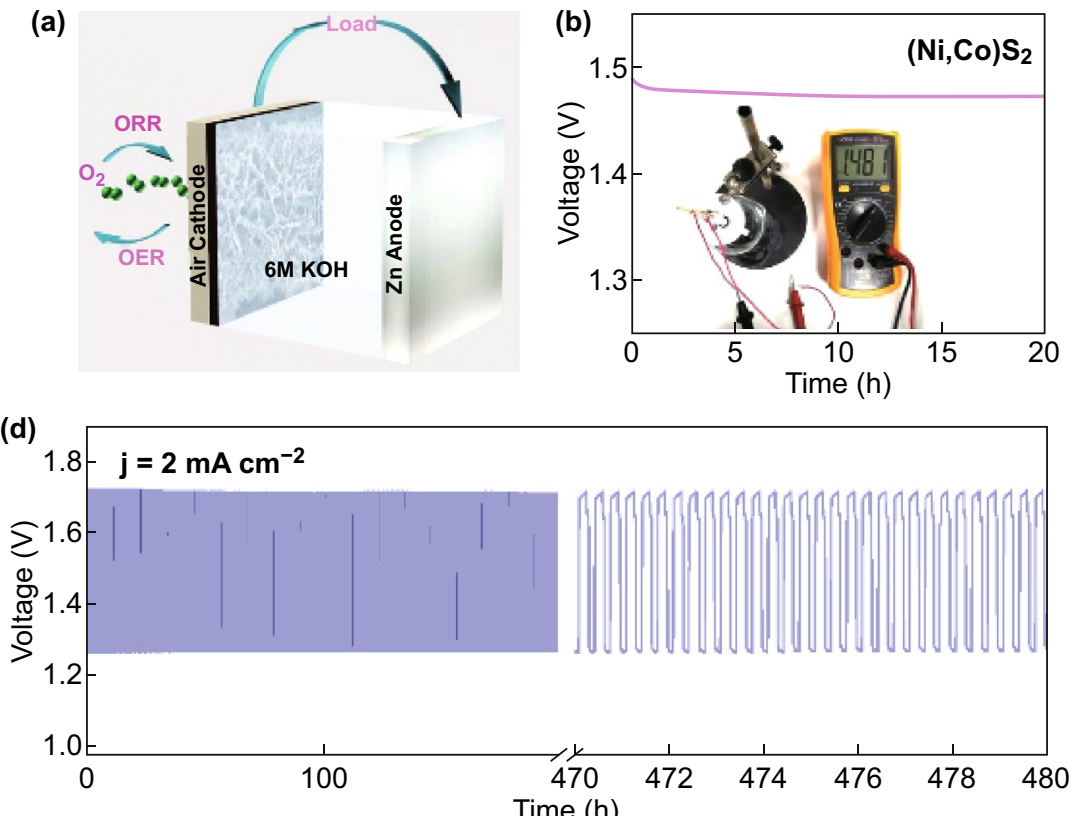
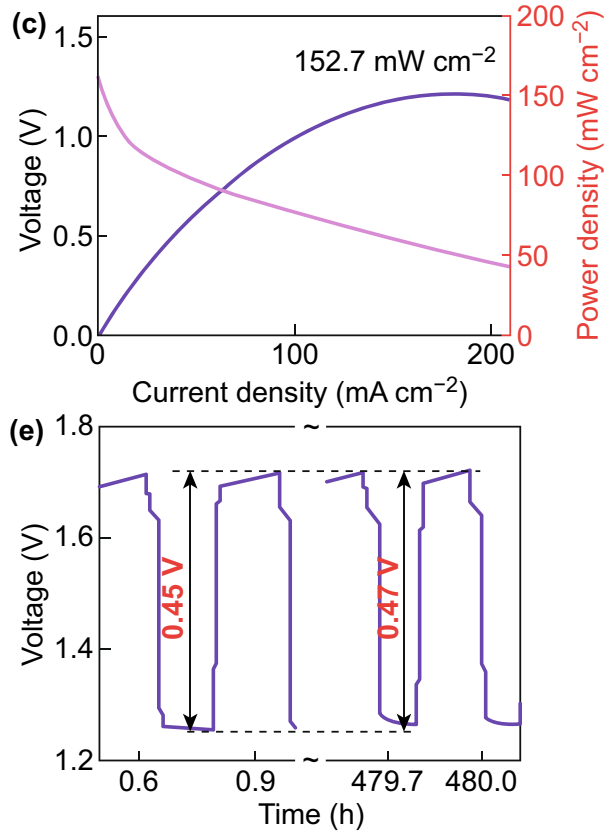
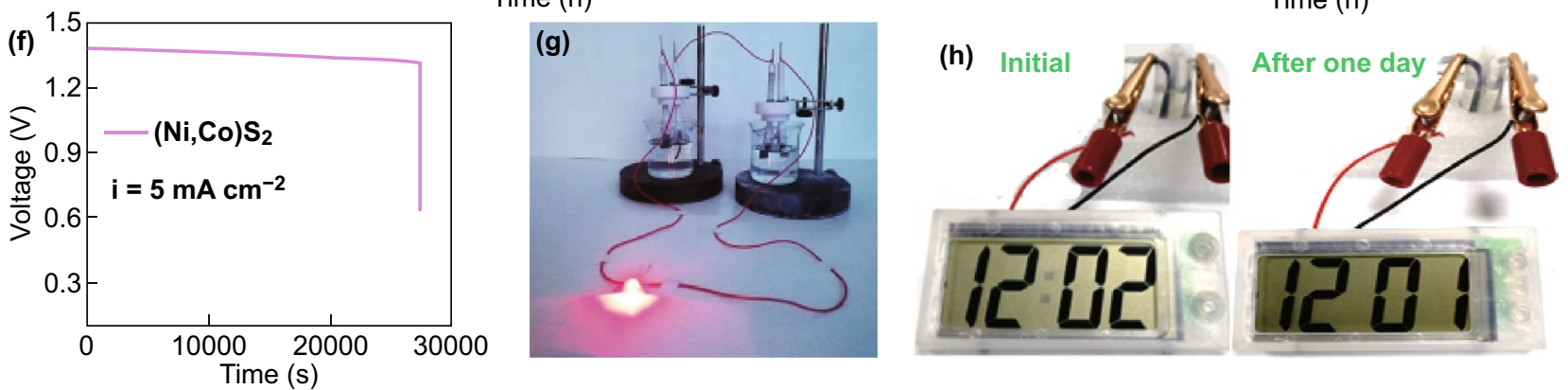

Fig. 5 a Schematic illustration of rechargeable $\mathrm{Zn}$-air battery. b Open cell voltage curve and c polarization and power density curves of $(\mathrm{Ni}, \mathrm{Co}) \mathrm{S}_{2}$-based primary $\mathrm{Zn}$-air battery. d Galvanostatic discharge-charge cycling curves at $2 \mathrm{~mA} \mathrm{~cm}^{-2}$ of the rechargeable $\mathrm{Zn}$-air battery. e Charge-discharge efficiency of the $\mathrm{Zn}$-air battery at the beginning and end. $\mathbf{f}$ Long-time discharge curves of $(\mathrm{Ni}, \mathrm{Co}) \mathrm{S}_{2}$-based $\mathrm{Zn}$-air battery at $5 \mathrm{~mA} \mathrm{~cm}{ }^{-2}$. g Photograph of red LED powered by two $(\mathrm{Ni}, \mathrm{Co}) \mathrm{S}_{2}$-based $\mathrm{Zn}$-air batteries. $\mathbf{h}$ Photographs of an electronic watch powered by the $(\mathrm{Ni}, \mathrm{Co}) \mathrm{S}_{2}$-based Zn-air battery

We also characterized the electrocatalytic HER properties of the three samples. As shown in Fig. 6a, the onset overpotential of $(\mathrm{Ni}, \mathrm{Co}) \mathrm{S}_{2}$ is $180 \mathrm{mV}$, which is lower than that of $\mathrm{NiS}_{2}(\sim 264 \mathrm{mV})$ and $\mathrm{CoS}_{2}(\sim 237 \mathrm{mV})$. When the current density reaches $10 \mathrm{~mA} \mathrm{~cm}^{-2}, \mathrm{NiS}_{2}$ and $\mathrm{CoS}_{2}$ require potentials of 298 and $254 \mathrm{mV}$, respectively, while $(\mathrm{Ni}, \mathrm{Co}) \mathrm{S}_{2}$ only requires $210 \mathrm{mV}$. In addition, the Tafel slope is $68 \mathrm{mV} \mathrm{dec}^{-1}$ for $(\mathrm{Ni}, \mathrm{Co}) \mathrm{S}_{2}$, which is smaller than that of $\mathrm{NiS}_{2}$ and $\mathrm{CoS}_{2}$ (Fig. 6b). Furthermore, $(\mathrm{Ni}, \mathrm{Co}) \mathrm{S}_{2}$ shows the largest $C_{\mathrm{dl}}$ of $40 \mathrm{mF} \mathrm{cm}^{-2}$ among the three samples and an excellent stability of more than 80,000 s for HER (Fig. S21, Table S7). Similarly, the HER polarization curve of $\mathrm{CoS}_{2}+\mathrm{NiS}_{2}$ is given in Fig. S22. Unsurprisingly, the physically mixed sample $\mathrm{CoS}_{2}+\mathrm{NiS}_{2}$ demonstrates an intermediate electrocatalytic hydrogen evolution efficiency. We also observed that $(\mathrm{Ni}, \mathrm{Co}) \mathrm{S}_{2}$ exhibits the best electrocatalytic properties among the three samples. The excellent reversibility makes it a very promising multifunctional catalyst. Furthermore, we used it as both cathode and anode to fabricate a watersplitting device. Figure $6 \mathrm{c}$ shows the schematic diagram of the self-assembled water-splitting unit powered by the $(\mathrm{Ni}, \mathrm{Co}) \mathrm{S}_{2}$-based $\mathrm{Zn}$-air battery. In this self-assembled device, the anode undergoes oxidation reaction to generate oxygen, and the cathode undergoes reduction reaction to produce hydrogen. As shown in Fig. 6d, the LSV curves of the overall water-splitting reactions of $(\mathrm{Ni}, \mathrm{Co}) \mathrm{S}_{2}$ show a $\Delta V\left(E_{\mathrm{OER}}-E_{\mathrm{HER}}\right)$ of 1.71 and $1.80 \mathrm{~V}$ at 10 and $50 \mathrm{~mA} \mathrm{~cm}^{-2}$, respectively, revealing a noticeable electrocatalytic performance of $(\mathrm{Ni}, \mathrm{Co}) \mathrm{S}_{2}$ in a water-splitting energy installation compared to many reported catalysts (Table S8). Figure 6e 

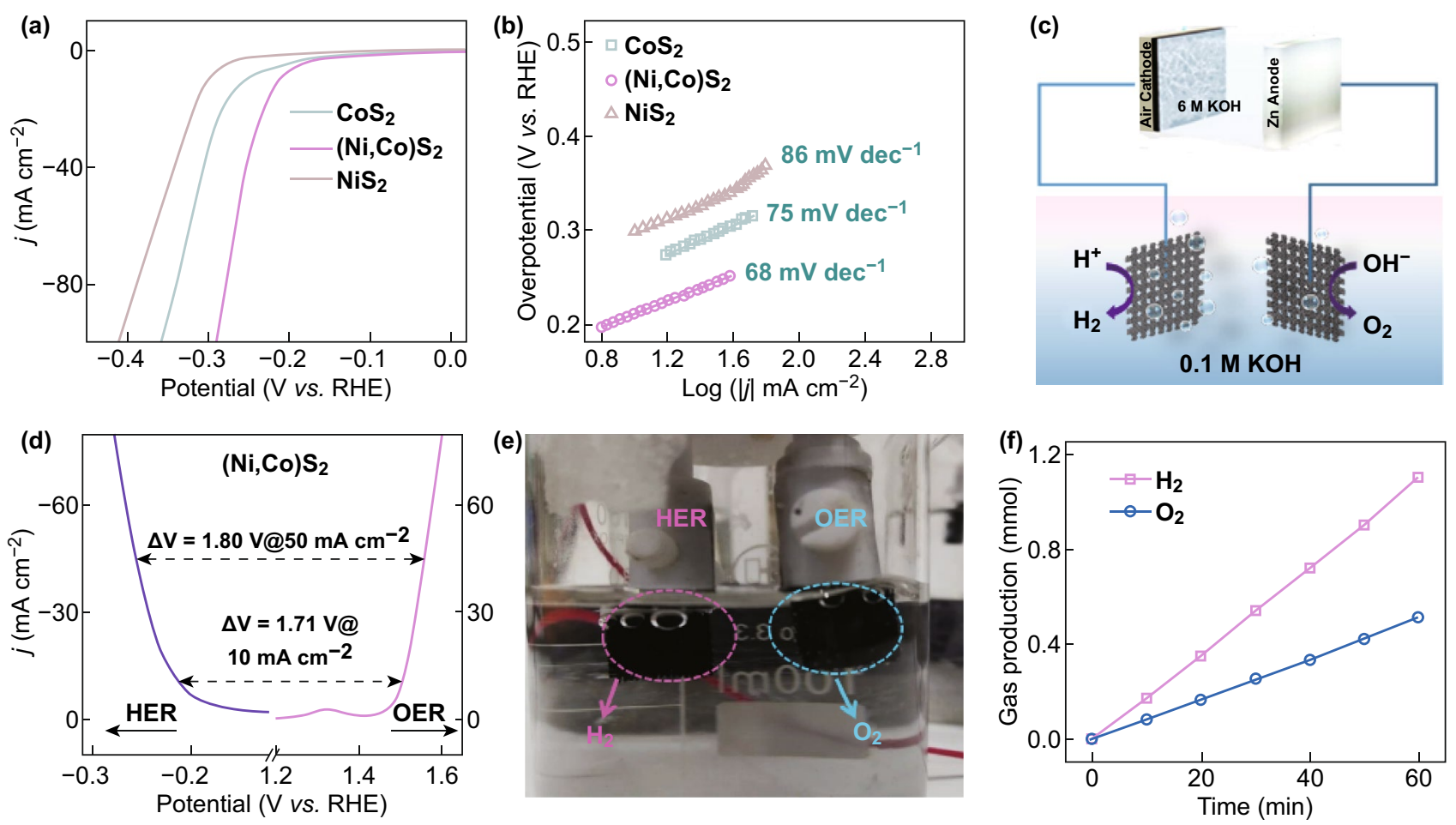

Fig. 6 a HER polarization curves of $(\mathrm{Ni}, \mathrm{Co}) \mathrm{S}_{2}, \mathrm{NiS}_{2}$, and $\mathrm{CoS}_{2}$ at $5 \mathrm{mV} \mathrm{s}^{-1}$ in $0.1 \mathrm{M} \mathrm{KOH}$. b Tafel slopes obtained from their polarization curves. c Schematic diagram of the self-assembled water-splitting system. $\mathbf{d}$ LSV curves of overall water splitting by $(\mathrm{Ni}, \mathrm{Co}) \mathrm{S}_{2}$ electrocatalyst in a two-electrode configuration at a scan rate of $5 \mathrm{mV} \mathrm{s}^{-1}$. e Two electrodes after water splitting powered by two in-series (Ni,Co)S $\mathrm{S}_{2}$-based $\mathrm{Zn}$-air batteries. $\mathbf{f}$ Time dependence of the mole quantities of $\mathrm{H}_{2}$ and $\mathrm{O}_{2}$ produced in the self-driven overall water-splitting unit

shows that the cathode reacts to produce hydrogen and the anode oxidizes to produce oxygen, and the $\mathrm{H}_{2}$ and $\mathrm{O}_{2}$ were collected by the drainage method. After $60 \mathrm{~min}$ of continuous reaction, the amounts of $\mathrm{H}_{2}$ and $\mathrm{O}_{2}$ collected were $1.15 \mathrm{mmol}$ and $0.57 \mathrm{mmol}$ (the ratio is $2: 1$ ), respectively. The output voltage stability of the self-assembled device was tested using a multimeter (Fig. S23). It can be seen that the output voltage stabilized after $1 \mathrm{~h}$ and did not reduce in the next hour, which reveals its good stability.

\section{Conclusions}

In summary, single-phase bimetallic $(\mathrm{Ni}, \mathrm{Co}) \mathrm{S}_{2}$ nanosheets were successfully synthesized by a hydrothermal route followed by thermal conversion to sulfide. With the purposely tuned nanosheet morphology, electronic structure, enhanced electrical conductivity, and active sites in the bimetallic sulfides, the $(\mathrm{Ni}, \mathrm{Co}) \mathrm{S}_{2}$ nanosheets demonstrated a superior electrocatalytic performance for oxygen evolution, oxygen reduction, and hydrogen evolution in an alkaline electrolyte.
First principle calculation results indicate that the adsorption of $\mathrm{HO}^{-}$to form ${ }^{*} \mathrm{OOH}$ on the $(\mathrm{Ni}, \mathrm{Co}) \mathrm{S}_{2}$ surface is the potential limiting step in the OER. When used as an electrode in a Zn-air battery, it demonstrated a small charge/ discharge voltage gap of $0.45 \mathrm{~V}$ at $2 \mathrm{~mA} \mathrm{~cm}^{-2}$, a high peak power density of $153.5 \mathrm{~mW} \mathrm{~cm} \mathrm{~cm}^{-2}$, a specific capacity of $842 \mathrm{mAh} \mathrm{g}_{\mathrm{Zn}}^{-1}$ at $5 \mathrm{~mA} \mathrm{~cm}{ }^{-2}$, and excellent cycling stability even after $480 \mathrm{~h}$. The high efficiency demonstrates the application potential of the rechargeable $\mathrm{Zn}$-air battery in powering an electrochemical water-splitting unit made of the same $(\mathrm{Ni}, \mathrm{Co}) \mathrm{S}_{2}$ nanosheets as both the electrodes, which exhibited a low cell voltage of $1.71 \mathrm{~V}$ at $10 \mathrm{~mA} \mathrm{~cm}$ cm $^{-2}$. This work is helpful for improving the $\mathrm{Zn}$-air battery performance and the utilization of new energy in the future.

Acknowledgements This work is supported by the National Natural Science Foundation of China (Grant Nos. 11474137 and 11674143), Program for Changjiang Scholars and Innovative Research Team in University (IRT 16R35), the Fundamental Research Funds for the Central Universities (Grant Nos. LZUMMM2018017, lzujbky-2018-121). John Wang acknowledges the support of Ministry of Education (MOE2016-T2-2-138, 
Singapore), for research conducted at the National University of Singapore.

Open Access This article is distributed under the terms of the Creative Commons Attribution 4.0 International License (http:// creativecommons.org/licenses/by/4.0/), which permits unrestricted use, distribution, and reproduction in any medium, provided you give appropriate credit to the original author(s) and the source, provide a link to the Creative Commons license, and indicate if changes were made.

Electronic supplementary material The online version of this article (https://doi.org/10.1007/s40820-018-0232-2) contains supplementary material, which is available to authorized users.

\section{References}

1. J.S. Lee, G. Nam, J. Sun, S. Higashi, H.W. Lee, S. Lee, W. Chen, Y. Cui, J. Cho, Composites of a prussian blue analogue and gelatin-derived nitrogen-doped carbon-supported porous spinel oxides as electrocatalysts for a $\mathrm{Zn}$-air battery. Adv. Energy Mater. 6(22), 1601052 (2016). https://doi.org/10.1002/ aenm.201601052

2. H. Wang, H.W. Lee, Y. Deng, Z. Lu, P.C. Hsu, Y. Liu, D. Lin, Y. Cui, Bifunctional non-noble metal oxide nanoparticle electrocatalysts through lithium-induced conversion for overall water splitting. Nat. Commun. 6, 7261 (2015). https://doi. org/10.1038/ncomms8261

3. J. Wang, W. Cui, Q. Liu, Z. Xing, A.M. Asiri, X. Sun, Recent progress in cobalt-based heterogeneous catalysts for electrochemical water splitting. Adv. Mater. 28(2), 215-230 (2016). https://doi.org/10.1002/adma.201502696

4. F. Meng, H. Zhong, D. Bao, J. Yan, X. Zhang, In situ coupling of strung $\mathrm{Co}_{4} \mathrm{~N}$ and intertwined $\mathrm{N}-\mathrm{C}$ fibers toward freestanding bifunctional cathode for robust, efficient, and flexible Zn-air batteries. J. Am. Chem. Soc. 138(32), 10226-10231 (2016). https://doi.org/10.1021/jacs.6b05046

5. C. Lin, S.S. Shinde, Y. Wang, Y. Sun, S. Chen, H. Zhang, J.H. Lee, Flexible and rechargeable $\mathrm{Zn}$-air batteries based on green feedstocks with $75 \%$ round-trip efficiency. Sustain. Energy Fuels 1(9), 1909-1914 (2017). https://doi.org/10.1039/ C7SE00346C

6. J.S. Lee, S. Tai Kim, R. Cao, N.S. Choi, M. Liu, K.T. Lee, J. Cho, Metal-air batteries with high energy density: Li-air versus Zn-air. Adv. Energy Mater. 1(1), 34-50 (2011). https ://doi.org/10.1002/aenm.201000010

7. B.Y. Xia, Y. Yan, N. Li, H.B. Wu, X.W. Lou, X. Wang, A metal-organic framework-derived bifunctional oxygen electrocatalyst. Nat. Energy 1(1), 15006 (2016). https://doi. org/10.1038/nenergy.2015.6

8. T. Liu, X. Ma, D. Liu, S. Hao, G. Du et al., Mn doping of cop nanosheets array: an efficient electrocatalyst for hydrogen evolution reaction with enhanced activity at all $\mathrm{pH}$ values.
ACS Catal. 7(1), 98-102 (2016). https://doi.org/10.1021/acsca tal.6b02849

9. P.W. Menezes, A. Indra, C. Das, C. Walter, C. Göbel, V. Gutkin, D. Schmeißer, M. Driess, Uncovering the nature of active species of nickel phosphide catalysts in high-performance electrochemical overall water splitting. ACS Catal. 7(1), 103-109 (2016). https://doi.org/10.1021/acscatal.6b02666

10. L. Bu, N. Zhang, S. Guo, X. Zhang, J. Li et al., Biaxially strained $\mathrm{PtPb} / \mathrm{Pt}$ core/shell nanoplate boosts oxygen reduction catalysis. Science 354(6318), 1410-1414 (2016). https://doi. org/10.1126/science.aah6133

11. S.T. Hunt, M. Milina, A.C. Alba-Rubio, C.H. Hendon, J.A. Dumesic, Y. Román-Leshkov, Self-assembly of noble metal monolayers on transition metal carbide nanoparticle catalysts. Science 352(6288), 974-978 (2016). https://doi.org/10.1126/ science.aad 8471

12. J. Li, W. Xu, J. Luo, D. Zhou, D. Zhang, L. Wei, D. Yuan, Synthesis of 3D hexagram-like cobalt-manganese sulfides nanosheets grown on nickel foam: a bifunctional electrocatalyst for overall water splitting. Nano-Micro Lett. 10(1), 6 (2018). https://doi.org/10.1007/s40820-017-0160-6

13. J. Masa, W. Xia, I. Sinev, A. Zhao, Z. Sun, S. Grutzke, P. Weide, M. Muhler, W. Schuhmann, Solution-cast metal oxide thin film electrocatalysts for oxygen evolution. J. Am. Chem. Soc. 134(41), 17253-17261 (2012). https://doi.org/10.1021/ ja307507a

14. J. Yin, Y. Li, F. Lv, Q. Fan, Y.Q. Zhao et al., NiO/CoN porous nanowires as efficient bifunctional catalysts for $\mathrm{Zn}$-air batteries. ACS Nano 11(2), 2275-2283 (2017). https://doi. org/10.1021/acsnano.7b00417

15. J.X. Feng, L.X. Ding, S.H. Ye, X.J. He, H. Xu, Y.X. Tong, G.R. Li, $\mathrm{Co}(\mathrm{OH})_{2} @$ PANI hybrid nanosheets with 3D networks as high-performance electrocatalysts for hydrogen evolution reaction. Adv. Mater. 27(44), 7051-7057 (2015). https ://doi.org/10.1002/adma.201503187

16. H. Xia, J. Zhang, Z. Yang, S. Guo, S. Guo, Q. Xu, 2D MOF nanoflake-assembled spherical microstructures for enhanced supercapacitor and electrocatalysis performances. NanoMicro Lett. 9(4), 43 (2017). https://doi.org/10.1007/s4082 0-017-0144-6

17. H. Zhang, X. Li, A. Hähnel, V. Naumann, C. Lin, S. Azimi, R.B. Wehrspohn, Bifunctional heterostructure assembly of $\mathrm{NiFe} \mathrm{LDH}$ nanosheets on $\mathrm{NiCoP}$ nanowires for highly efficient and stable overall water splitting. Adv. Funct. Mater. 28(14), 1706847 (2018). https://doi.org/10.1002/adfm.201706847

18. Z. Liu, Y. Wang, R. Chen, C. Chen, H. Yang, J. Ma, S. Wang, Quaternary bimetallic phosphosulphide nanosheets derived from prussian blue analogues: origin of the ultra-high activity for oxygen evolution. J. Power Sources 403, 90-96 (2018). https://doi.org/10.1016/j.jpowsour.2018.09.078

19. Y. Liang, Y. Li, H. Wang, J. Zhou, J. Wang, T. Regier, H. Dai, $\mathrm{Co}_{3} \mathrm{O}_{4}$ nanocrystals on graphene as a synergistic catalyst for oxygen reduction reaction. Nat. Mater. 10(10), 780-786 (2011). https://doi.org/10.1038/nmat3087

20. J. Wang, K. Li, H.X. Zhong, D. Xu, Z.L. Wang, Z. Jiang, X.B. Zhang, Synergistic effect between metal-nitrogen-carbon 
sheets and $\mathrm{NiO}$ nanoparticles for enhanced electrochemical water-oxidation performance. Angew. Chem. Int. Ed. 54(36), 10530-10534 (2015). https://doi.org/10.1002/anie.201504358

21. C. Lin, S.S. Shinde, Z. Jiang, X. Song, Y. Sun, L. Guo, J.H. Lee, In situ directional formation of $\mathrm{Co} @ \mathrm{CoO}_{x}$ embedded 1D carbon nanotubes as an efficient oxygen electrocatalyst for ultra-high rate $\mathrm{Zn}$-air batteries. J. Mater. Chem. A 5(27), 13994-14002 (2017). https://doi.org/10.1039/C7TA02215H

22. J. Jiang, M. Gao, W. Sheng, Y. Yan, Hollow chevrel-phase $\mathrm{NiMo}_{3} \mathrm{~S}_{4}$ for hydrogen evolution in alkaline electrolytes. Angew. Chem. Int. Ed. 55(49), 15240-15245 (2016). https:// doi.org/10.1002/anie.201607651

23. G. Li, D. Zhang, Q. Qiao, Y. Yu, D. Peterson et al., All the catalytic active sites of $\mathrm{MoS}_{2}$ for hydrogen evolution. J. Am. Chem. Soc. 138(51), 16632-16638 (2016). https://doi. org/10.1021/jacs.6b05940

24. L. Jia, X. Sun, Y. Jiang, S. Yu, C. Wang, A novel $\mathrm{MoSe}_{2}$-reduced graphene oxide/polyimide composite film for applications in electrocatalysis and photoelectrocatalysis hydrogen evolution. Adv. Funct. Mater. 25(12), 1814-1820 (2015). https://doi.org/10.1002/adfm.201401814

25. F. Wang, Y. Li, T.A. Shifa, K. Liu, F. Wang, Z. Wang, J. He, Selenium-enriched nickel selenide nanosheets as a robust electrocatalyst for hydrogen generation. Angew. Chem. Int. Ed. 55(24), 6919-6924 (2016). https://doi.org/10.1002/anie.20160 2802

26. H. Yan, C. Tian, L. Wang, A. Wu, M. Meng, L. Zhao, H. Fu, Phosphorus-modified tungsten nitride/reduced graphene oxide as a high-performance, non-noble-metal electrocatalyst for the hydrogen evolution reaction. Angew. Chem. Int. Ed. 54(21), 6325-6329 (2015). https://doi.org/10.1002/anie.201501419

27. B. Zhang, C. Xiao, S. Xie, J. Liang, X. Chen, Y. Tang, Ironnickel nitride nanostructures in situ grown on surface-redoxetching nickel foam: efficient and ultrasustainable electrocatalysts for overall water splitting. Chem. Mater. 28(19), 6934-6941 (2016). https://doi.org/10.1021/acs.chemm ater.6b02610

28. L. Kuai, J. Geng, C. Chen, E. Kan, Y. Liu, Q. Wang, B. Geng, A reliable aerosol-spray-assisted approach to produce and optimize amorphous metal oxide catalysts for electrochemical water splitting. Angew. Chem. Int. Ed. 53(29), 7547-7551 (2014). https://doi.org/10.1002/anie.201404208

29. P. Chen, K. Xu, T. Zhou, Y. Tong, J. Wu et al., Strong-coupled cobalt borate nanosheets/graphene hybrid as electrocatalyst for water oxidation under both alkaline and neutral conditions. Angew. Chem. Int. Ed. 55(7), 2488-2492 (2016). https://doi. org/10.1002/anie.201511032

30. Y. Jia, L. Zhang, G. Gao, H. Chen, B. Wang et al., Heterostructure coupling of exfoliated $\mathrm{Ni}-\mathrm{Fe}$ hydroxide nanosheet and defective graphene as a bifunctional electrocatalyst for overall water splitting. Adv. Mater. 29(17), 1700017 (2017). https://doi.org/10.1002/adma.201700017

31. Y. Wang, M. Qiao, Y. Li, S. Wang, Tuning surface electronic configuration of NiFe LDHs nanosheets by introducing cation vacancies $(\mathrm{Fe}$ or $\mathrm{Ni}$ ) as highly efficient electrocatalysts for oxygen evolution reaction. Small 14(17), 1800136 (2018). https://doi.org/10.1002/smll.201800136

32. Z.L. Wang, X.F. Hao, Z. Jiang, X.P. Sun, D. Xu, J. Wang, X.B. Zhang, $\mathrm{C}$ and $\mathrm{N}$ hybrid coordination derived $\mathrm{Co}-\mathrm{C}-\mathrm{N}$ complex as a highly efficient electrocatalyst for hydrogen evolution reaction. J. Am. Chem. Soc. 137(48), 15070-15073 (2015). https://doi.org/10.1021/jacs.5b09021

33. K.H. Liu, H.X. Zhong, S.J. Li, Y.X. Duan, M.M. Shi, X.B. Zhang, Q. Jiang, Advanced catalysts for sustainable hydrogen generation and storage via hydrogen evolution and carbon dioxide/nitrogen reduction reactions. Prog. Mater Sci. 92, 64 (2018). https://doi.org/10.1016/j.pmatsci.2017.09.001

34. D. Liu, L. Tao, D. Yan, Y. Zou, S. Wang, Recent advances on non-precious metal porous carbon-based electrocatalysts for oxygen reduction reaction. Chem. Electro. Chem. 5(14), 1775-1785 (2018). https://doi.org/10.1002/celc.201800086

35. J. Yin, Y. Li, F. Lv, M. Lu, K. Sun et al., Oxygen vacancies dominated $\mathrm{NiS}_{2} / \mathrm{CoS}_{2}$ interface porous nanowires for portable $\mathrm{Zn}$-air batteries driven water splitting devices. Adv. Mater. 29(47), 1704681 (2017). https://doi.org/10.1002/adma.20170 4681

36. N. Kornienko, J. Resasco, N. Becknell, C.M. Jiang, Y.S. Liu et al., Operando spectroscopic analysis of an amorphous cobalt sulfide hydrogen evolution electrocatalyst. J. Am. Chem. Soc. 137(23), 7448-7455 (2015). https://doi.org/10.1021/ jacs.5b03545

37. H. Liu, Q. He, H. Jiang, Y. Lin, Y. Zhang, M. Habib, S. Chen, L. Song, Electronic structure reconfiguration toward pyrite $\mathrm{NiS}_{2}$ via engineered heteroatom defect boosting overall water splitting. ACS Nano 11(11), 11574-11583 (2017). https://doi. org/10.1021/acsnano.7b06501

38. Y. Qu, M. Yang, J. Chai, Z. Tang, M. Shao et al., Facile synthesis of vanadium-doped $\mathrm{Ni}_{3} \mathrm{~S}_{2}$ nanowire arrays as active electrocatalyst for hydrogen evolution reaction. ACS Appl. Mater. Interfaces 9(7), 5959-5967 (2017). https://doi. org/10.1021/acsami.6b13244

39. J. Zhang, Y. Liu, C. Sun, P. Xi, S. Peng, D. Gao, D. Xue, Accelerated hydrogen evolution reaction in $\mathrm{CoS}_{2}$ by transitionmetal doping. ACS Energy Lett. 3(4), 779-786 (2018). https ://doi.org/10.1021/acsenergylett.8b00066

40. J. Zhang, B. Xiao, X. Liu, P. Liu, P. Xi, W. Xiao, J. Ding, D. Gao, D. Xue, Copper dopants improved the hydrogen evolution activity of earth-abundant cobalt pyrite catalysts by activating the electrocatalytically inert sulfur sites. J. Mater. Chem. A 5(33), 17601-17608 (2017). https://doi.org/10.1039/ C7TA05433E

41. M. Caban-Acevedo, M.L. Stone, J.R. Schmidt, J.G. Thomas, Q. Ding, H.C. Chang, M.L. Tsai, J.H. He, S. Jin, Efficient hydrogen evolution catalysis using ternary pyrite-type cobalt phosphosulphide. Nat. Mater. 14(12), 1245-1251 (2015). https ://doi.org/10.1038/nmat4410

42. H. Liang, A.N. Gandi, D.H. Anjum, X. Wang, U. Schwingenschlogl, H.N. Alshareef, Plasma-assisted synthesis of NiCoP for efficient overall water splitting. Nano Lett. 16(12), 77187725 (2016). https://doi.org/10.1021/acs.nanolett.6b03803 
43. K. Liang, K. Marcus, S. Zhang, L. Zhou, Y. Li, S.T. De Oliveira, N. Orlovskaya, Y.H. Sohn, Y. Yang, $\mathrm{NiS}_{2} / \mathrm{FeS}$ holey film as freestanding electrode for high-performance lithium battery. Adv. Energy Mater. 7(22), 1701309 (2017). https:// doi.org/10.1002/aenm.201701309

44. H. Zhang, Y. Li, T. Xu, J. Wang, Z. Huo, P. Wan, X. Sun, Amorphous Co-doped $\mathrm{MoS}_{2}$ nanosheet coated metallic $\mathrm{CoS}_{2}$ nanocubes as an excellent electrocatalyst for hydrogen evolution. J. Mater. Chem. A 3(29), 15020-15023 (2015). https:// doi.org/10.1039/C5TA03410H

45. X. Zhang, W.P. Han, J.B. Wu, S. Milana, Y. Lu, Q.Q. Li, P.H. Tan, Shear and layer breathing modes in multilayer $\mathrm{MoS}_{2}$. Phys. Rev. B 87(11), 1504-1509 (2012). https://doi. org/10.1103/PhysRevB.87.115413

46. J. Zhang, W. Xiao, P. Xi, S. Xi, Y. Du, D. Gao, J. Ding, Activating and optimizing activity of $\mathrm{CoS}_{2}$ for hydrogen evolution reaction through the synergic effect of $\mathrm{N}$ dopants and $\mathrm{S}$ vacancies. ACS Energy Lett. 2(5), 1022-1028 (2017). https://doi. org/10.1021/acsenergylett.7b00270

47. L. Hou, Y. Shi, C. Wu, Y. Zhang, Y. Ma, X. Sun, J. Sun, X. Zhang, C. Yuan, Monodisperse metallic $\mathrm{NiCoSe}_{2}$ hollow sub-microspheres: formation process, intrinsic charge-storage mechanism, and appealing pseudocapacitance as highly conductive electrode for electrochemical supercapacitors. Adv. Funct. Mater. 28(13), 1705921 (2018). https://doi.org/10.1002/ adfm.201705921

48. X. Xu, H. Liang, F. Ming, Z. Qi, Y. Xie, Z. Wang, Prussian blue analogues derived penroseite $(\mathrm{Ni}, \mathrm{Co}) \mathrm{Se}_{2}$ nanocages anchored on 3D graphene aerogel for efficient water splitting. ACS Catal. 7(9), 6394-6399 (2017). https://doi.org/10.1021/ acscatal.7b02079

49. D. Susac, L. Zhu, M. Teo, A. Sode, K.C. Wong, P.C. Wong, S.A. Campbell, Characterization of $\mathrm{FeS}_{2}$-based thin films as model catalysts for the oxygen reduction reaction. J. Phys. Chem. C 111(50), 18715-18723 (2007). https://doi. org/10.1021/jp073395i

50. T. Meng, J. Qin, S. Wang, D. Zhao, B. Mao, M. Cao, In situ coupling of $\mathrm{Co}_{0.85} \mathrm{Se}$ and $\mathrm{n}$-doped carbon via one-step selenization of metal-organic frameworks as a trifunctional catalyst for overall water splitting and $\mathrm{Zn}$-air batteries. J. Mater. Chem. A 5(15), 7001-7014 (2017). https://doi. org/10.1039/C7TA01453H

51. D. Yoon, B. Seo, J. Lee, K.S. Nam, B. Kim, S. Park, H. Baik, $\mathrm{S}$. Hoon Joo, K. Lee, Facet-controlled hollow $\mathrm{RhS}_{2}$ hexagonal nanoprisms as highly active and structurally robust catalysts toward hydrogen evolution reaction. Energy Environ. Sci. 9(3), 850-856 (2016). https://doi.org/10.1039/C5EE03456F

52. J. Miao, F.X. Xiao, H.B. Yang, S.Y. Khoo, J. Chen, Z. Fan, B. Liu, Hierarchical Ni-Mo-S nanosheets on carbon fiber cloth: a flexible electrode for efficient hydrogen generation in neutral electrolyte. Sci. Adv. 1(7), e1500259 (2015). https://doi. org/10.1126/sciadv. 1500259

53. J. Xie, H. Zhang, S. Li, R. Wang, X. Sun, M. Zhou, J. Zhou, X.W. Lou, Y. Xie, Defect-rich $\mathrm{MoS}_{2}$ ultrathin nanosheets with additional active edge sites for enhanced electrocatalytic hydrogen evolution. Adv. Mater. 25(40), 5807-5813 (2013). https://doi.org/10.1002/adma.201302685

54. Y. Li, J. Yin, L. An, M. Lu, K. Sun, Y.Q. Zhao, P. Xi, Metallic $\mathrm{CuCo}_{2} \mathrm{~S}_{4}$ nanosheets of atomic thickness as efficient bifunctional electrocatalysts for portable, flexible $\mathrm{Zn}$-air batteries. Nanoscale 10(14), 6581-6588 (2018). https://doi.org/10.1039/ C8NR01381K

55. J. Rossmeisl, Z.W. Qu, H. Zhu, G.J. Kroes, J.K. Nørskov, Electrolysis of water on oxide surfaces. J. Electroanal. Chem. 607(1-2), 83-89 (2007). https://doi.org/10.1016/j.jelec hem.2006.11.008

56. P. Liu, D. Gao, W. Xiao, L. Ma, K. Sun, P. Xi, D. Xue, J. Wang, Self-powered water-splitting devices by core-shell NiFe@N-graphite-based Zn-air batteries. Adv. Funct. Mater. 28(14), 1706928 (2018). https://doi.org/10.1002/adfm.20170 6928

57. C. Hu, L. Dai, Multifunctional carbon-based metal-free electrocatalysts for simultaneous oxygen reduction, oxygen evolution, and hydrogen evolution. Adv. Mater. 29(9), 1604942 (2017). https://doi.org/10.1002/adma.201604942 